\title{
Comparative Analysis of the Percentage of Patents Requested by the Latin American Countries of Group 1 of the SIR Iber 2019 Ranking
}

Authors: Marisabel Luna Cardozo, Jorge Armando Mendoza Hernandez, Darwin Solano

\begin{abstract}
:
The production and dissemination of scientific documents from university education institutions in Andorra, Spain, Portugal, and Latin American countries based on research, innovation, and social impact measurement factors are shown in the SIR Iber reports. This paper analyzes and compares the percentage of patents requested by the Latin American countries of group 1 of the SIR Iber 2019 report, in order to contrast the results of the RICYT and the same SIR Iber 2019 report, through the databases of the WIPO PCT agreement and PATSTAT, respectively, as measures of the performance of each country in the development of patents. The countries are located in the same order: Spain, Brazil, Mexico, Portugal, Chile, Colombia, and Argentina, from highest to lowest, according to the number of patents requested in the SIR Iber 2019 and RICYT report, although the percentage figures do not coincide, despite the fact that the WIPO PCT agreement uses as a source of statistical data extracted/compiled from the PATSTAT database. Furthermore, for Spain and Brazil, an annual decrease in the number of patents requested through the WIPO PCT agreement is predicted and, simultaneously, for Mexico, Chile, and Colombia, an increase per year is expected.
\end{abstract}

Keywords:

Patents requested, SIR Iber 2019, OMPI, RICYT, PATSTAT, Innovation

DOI: https://doi.org/10.1007/978-981-33-4183-8 11 